\title{
Clinical guideline recommendations for antipsychotic long-acting injections
}

John M. Kane and Carlos Garcia-Ribera

\section{Background}

Long-acting injections (LAIS) of antipsychotic drugs were developed over 40 years ago in an attempt to improve the long-term treatment of schizophrenia.

\section{Aims}

To review existing guidelines concerning antipsychotic use generally, and LAls in particular, and how patients might be identified as potential candidates for LAl treatment.

\section{Method}

Literature review.

\section{Results}

Currently several first-generation and one second-generation antipsychotic LAls are available, with others under development. Although the use of LAls is widespread around the world, patterns of use vary widely. Important considerations regarding the use of LAls include the indications for long-term pharmacotherapy in schizophrenia in general, the indications for LAls, the risks associated with LAls, the need to update guidelines and the issue of cost.

\section{Conclusions}

The use of these injections in first-episode psychosis and treatment-refractory schizophrenia is not currently a focus of recommendations, but should be considered. Long-acting injections remain an underutilised option in many countries despite frequent non-adherence with oral medication and subsequent relapse.

\section{Declaration of interest}

J.K. has been a consultant to or member of an advisory board for Abbott, AstraZeneca, Bristol-Myers Squibb, Cephalon, Eli Lilly, Janssen, Johnson \& Johnson, Lundbeck, Otsuka, Pfizer, PGXHealth, Proteus, Vanda and Wyeth; he is a member of the speakers bureau for Astrazeneca, BristolMyers Squibb, Eli Lilly and Janssen-Cilag. C.G.R. has been a consultant to AstraZeneca, Bristol-Myers Squibb, Otsuka and Sanofi-Synthelabo; he has been a speaker for Astrazeneca, Bristol-Myers Squibb, Eli Lilly, Novartis, Otsuka and SanofiSynthelabo.
Antipsychotic long-acting injections (LAIs) were introduced in 1966 in an attempt to improve the long-term treatment of schizophrenia. We have previously participated in the development of guidelines for the use of injectable antipsychotic agents. ${ }^{1}$ Although LAIs are widely prescribed around the world, there remains concern that there may be patients who might benefit from such formulations who do not currently receive an appropriate trial. With the introduction of a long-acting injectable formulation of risperidone, and the likely availability of LAI forms of olanzapine and paliperidone in the near future, there are more choices available to clinicians and patients. In this article we review the existing guidelines for the use of LAIs in schizophrenia and discuss how further perspectives have evolved over the decade since their publication. Important considerations include the indications for long-term pharmacotherapy in schizophrenia in general, the indications for LAIs, the issue of cost, the potential use of LAIs in first-episode or early-phase illness and the potential role of LAIs in treatment-refractory disorder.

\section{Need for long-term treatment of schizophrenia}

As more and more studies have been conducted over the past several decades, controversy regarding the indications and contraindications for antipsychotics in general has diminished. It is widely accepted that antipsychotic medications are indicated for both short-term and long-term treatment of schizophrenia, regardless of the subtype, patient age, type of onset or presence of comorbid psychiatric conditions. There is, however, less unanimity regarding the appropriate duration of treatment, particularly for individuals who have experienced only one episode of illness (see Table 1).

It was not until the 1980s that placebo-controlled trials of maintenance treatment following a single episode were first conducted. ${ }^{2,3}$ These studies were generally of relatively short duration (1-2 years), given the potential and expected duration of a schizophrenic illness. ${ }^{4}$ Although these trials, coupled with more naturalistic assessment of relapse prevention, ${ }^{5}$ support the superiority of continued antipsychotic medication in comparison with placebo or no treatment, the relapse rates even on placebo were generally substantially lower than those observed under placebo treatment following multiple episodes of illness. This observation suggested that a substantial subgroup of people with first-episode disorder are not at risk of relapse when medications are discontinued for a year or more, and called into question the relative necessity, or benefit-to-risk ratio, of long-term treatment following a single episode. For example, Robinson et al reported that $18 \%$ of patients followed for up to 5 years after symptomatic recovery from their first episode had not experienced a second episode. ${ }^{5}$ However, at the same time these investigators reported a five times higher relapse rate among those who discontinued medication compared with those who continued. Kane et al reported a $40 \%$ relapse rate on placebo after 1 year in comparison with none on active medication. ${ }^{2}$ These data suggest that a minority might not need medication to prevent relapse, but we have as yet no way of identifying such patients. The data from long-term follow-up studies also emphasise the potential heterogeneity of outcome in schizophrenia, with or without medication. ${ }^{6,7}$ It is important to recognise that long-term exposure to medications is generally not without risk. Concerns regarding the development of tardive dyskinesia, ${ }^{8}$ and more recently endocrine and metabolic adverse effects, ${ }^{9}$ have also influenced the benefit-to-risk ratio of long-term treatments.

A further complication in considering the indications for long-term pharmacotherapy in the management of schizophrenia involves the nature of the illness itself and its potential impact on cognitive functioning, insight, propensity to suicide or violent behaviour and comorbid substance misuse, as well as social and vocational functioning. An illness in which an exacerbation can 


\begin{tabular}{|c|c|c|c|c|c|c|}
\hline Guidelines & Year & Country & Funding & Recommendation & $\begin{array}{l}\text { Single } \\
\text { episode }\end{array}$ & $\begin{array}{l}\text { Multiple } \\
\text { episode }\end{array}$ \\
\hline $\begin{array}{l}\text { Schizophrenia Patient Outcomes } \\
\text { Research Team Treatment } \\
\text { Recommendations }^{10}\end{array}$ & 1998 & USA & $\begin{array}{l}\text { Agency for Health Care } \\
\text { Policy and Research/ } \\
\text { NIMH }\end{array}$ & $\begin{array}{l}\text { At least } 1 \text { year after remission of acute } \\
\text { phase with antipsychotic treatment }\end{array}$ & NS & NS \\
\hline $\begin{array}{l}\text { National Institute for Health and } \\
\text { Clinical Excellence }\end{array}$ & 2002 & UK & UK NHS & $\begin{array}{l}\text { In first-episode or acute psychosis at } \\
\text { least } 1-2 \text { years of treatment and } 2 \text { years } \\
\text { afterwards of monitoring }\end{array}$ & $1-2$ years & NS \\
\hline $\begin{array}{l}\text { Practice Guideline for the Treatment } \\
\text { of Patients with Schizophrenia }{ }^{12}\end{array}$ & 2004 & USA & $\begin{array}{l}\text { American Psychiatric } \\
\text { Association }\end{array}$ & $\begin{array}{l}\text { At least } 6 \text { months after stabilisation with } \\
\text { same treatment used in acute phase. } \\
\text { Indefinite treatment in multi-episode } \\
\text { or after two episodes in } 5 \text { years }\end{array}$ & $>6$ months & Indefinite \\
\hline $\begin{array}{l}\text { Clinical Practice Guidelines: } \\
\text { Treatment of Schizophrenia }^{13}\end{array}$ & 2005 & Canada & $\begin{array}{l}\text { Canadian Psychiatric } \\
\text { Association }\end{array}$ & $\begin{array}{l}\text { In first episode treatment for at least } \\
1-2 \text { years. In stable multi-episode at } \\
\text { least } 5 \text { years of stability }\end{array}$ & $1-2$ years & 5 years stable \\
\hline $\begin{array}{l}\text { Texas Medication Algorithm } \\
\text { Procedure }^{14}\end{array}$ & 2007 & USA & $\begin{array}{l}\text { Texas Department of } \\
\text { State Health Services }\end{array}$ & $\begin{array}{l}\text { No guidelines for discontinuation. In rare } \\
\text { cases after long remission (e.g. } 2 \text { years) }\end{array}$ & NS & NS \\
\hline
\end{tabular}

be associated with loss of insight and diminished interest in taking medication, as well as potential dangerousness to self and others, poses a somewhat different set of challenges from those associated with less complicated changes in health status. In essence, schizophrenia is a complex condition and the majority of patients need longer-term treatment because relapse is associated with significant personal costs (see Appendix 1).

\section{Guidelines for treatment of schizophrenia}

Table 1 provides a summary of the various guideline recommendations regarding duration of treatment following a single episode and those for multi-episode patients. In our view the guidelines are either overly conservative (i.e. too short in suggested duration) or inordinately vague in their recommendations, particularly as applied to patients with a single episode. Although placebo-controlled trials of maintenance treatment following a first episode have not lasted more than 2 years, there are prospective longitudinal studies that provide a valuable perspective. Robinson et al reported on a large cohort of patients with a first psychotic episode, and after 5 years of follow-up the single most powerful predictor of relapse was medication non-adherence. ${ }^{5}$ The relapse rate was five times higher among those who discontinued. That was true for the second as well as the first relapse. These and other data provide strong support for longer duration of treatment following a first episode. It is also important to consider the potential impact of a relapse on an individual at this phase of illness. Most patients who are appropriately treated following the onset of a first schizophrenic episode can be expected to have a good response to treatment, with the overwhelming majority achieving symptomatic remission within 6-12 months. ${ }^{4}$ It is ironic that individuals who are doing the best might also have the most to lose if they experience a relapse. Additionally, this is occurring in the context of the patient's (and family's) frequent difficulty accepting the reality of the illness and the potential hesitancy or ambivalence on the part of the clinical team to make strong recommendations (or even a definitive diagnosis).

\section{Guidelines regarding the use of long-acting injections}

Excerpts from five guidelines on the treatment of schizophrenia addressing the use of antipsychotic LAIs are given in Appendix $2 .{ }^{10-16}$ The guidelines are similar in their focus on patients who have demonstrated non-adherence or recurrent relapses related to partial or full non-adherence. They also highlight the importance of patient preference. The National Institute for Health and Clinical Excellence (NICE) guidelines suggest the possibility of a treatment plan in which the avoidance of covert non-adherence to the antipsychotic regimen is a priority, ${ }^{11}$ but in general the guidelines emphasise the use of LAIs after nonadherence has already been demonstrated and has been linked to repeated relapse.

\section{Who is an appropriate patient for antipsychotic LAls?}

Given the nature of the schizophrenic illness, the frequency and consequences of psychotic relapse and the high rates of non-adherence in medication-taking, it seems responsible to consider injectable antipsychotics as a potential strategy for many patients. There are individuals for whom a decision not to consider LAIs may be appropriate. The first is the patient who has consistently demonstrated his or her ability to take oral medication and chooses to continue doing so. The second is the individual who despite adequate discussion of potential benefits and risks, and sufficient psychoeducation regarding the nature of the illness, adamantly refuses even to try a long-acting formulation. The third is the patient unable to tolerate or unresponsive to the medications available in long-acting injectable formulations.

\section{Adherence}

\section{Clinical context}

The majority of patients with schizophrenia who are readmitted to hospital have exhibited some degree of non-adherence, and often it is unclear whether non-adherence preceded the relapse or was a consequence of it. ${ }^{17}$ The use of LAIs would allow clinicians to be certain whether a relapse occurred because of non-adherence or despite adequate medication. Clearly, this has important implications for subsequent treatment planning regarding the potential need to alter the dosage, the medication and the psychosocial treatment. When patients are receiving LAIs there is certainty as to a critical ingredient in the management of the illness. If a patient misses an injection there is immediate awareness on the part of the clinical team that an intervention is necessary, and yet there is also some time to act before a crisis is likely to ensue. 


\section{Comorbid substance misuse}

Substance misuse strongly predicts medication non-adherence. ${ }^{17,18}$ In cases of comorbid substance misuse the knowledge that the antipsychotic medication has definitely been taken, in the form of an LAI, is important in determining the cause of potential subsequent relapse.

\section{Psychosocial consequences}

Family relationships often suffer when uncertainty and anxiety associated with the potential for and the consequences of nonadherence weigh heavily on interactions. Many relatives and carers are directly involved in oral medication administration. Since they often face the initial burden (and even physical threat and danger) associated with a psychotic relapse, they are particularly sensitive to the issue of adherence. The use of LAI medication can provide enormous relief from this concern and facilitate the normalisation of family interactions.

\section{Inability to accurately predict non-adherence}

There are numerous reports evaluating the predictors and risk factors for non-adherence that have been assessed, but despite these efforts physicians in routine clinical practice are most often neither able to predict which patients are at risk nor able to identify which patients are actually failing to adhere to their medication regimen. Studies indicate that both patients and clinicians overestimate the degree of adherence. ${ }^{19,20}$ Therefore, we have to ask ourselves, given the availability of strategies to guarantee the potential benefits of continuous medication, why would we not avail ourselves and our patients of that potential advantage? In other words, what are the barriers to LAI prescribing?

\section{Research contexts}

There are a number of research contexts where certainty regarding adherence, by administering medication in the form of an LAI, enables the investigators to draw more valid conclusions about the research question posed. Examples include issues such as establishing the minimum effective dose for the prevention of relapse, ${ }^{21,22}$ evaluating the impact of family therapy on treatment outcome, ${ }^{23}$ and establishing the incidence and dosage-related risk of tardive dyskinesia. ${ }^{8}$ In all of these studies it would have been enormously difficult to draw meaningful conclusions without reasonable certainty that the participating patients were actually ingesting the prescribed dose of medication on a consistent basis.

\section{Key concerns}

\section{Clinician and patient attitudes}

Many clinicians are hesitant to use LAIs, for reasons discussed by, for example, Waddell \& Taylor. ${ }^{24}$ Can and should these attitudes be changed? Should physicians be more proactive in offering this option to patients, providing an evidence-based rationale, addressing concerns and the natural reluctance to receive injections in an appropriate, patient-oriented, shared decision-making fashion? Many guidelines suggest that the use of LAI formulations be considered when patients express a preference for them. This has always seemed to have a rather unfortunate or unintended implication. Do we really expect patients to readily express a preference for receiving medications by injection? This seems unlikely and it appears to put too much onus on patient preference. Given a preference, patients would prefer not to be ill in the first place. Certainly the use of LAI medication should (in all but legally influenced situations) be consistent with patient preference. However, the role of the clinical team, the family and the health delivery system in providing the evidence, the education, the support, the convenience and the financing is not irrelevant in determining patient preference. The discussion and shared decision-making around the use of long-acting medication should be part of an active engagement in working towards shared goals of recovery and wellness, ${ }^{25}$ not a single factor unnecessarily loaded with various misinformation, bias, avoidance of extra effort and so on, which can easily be ignored or dismissed under the rubric of 'patient preference'.

\section{Are people with first-episode psychosis candidates for LAIs?}

The guidelines and general practice tend to reserve LAI drugs for patients who have already experienced significant sequelae of non-adherence, e.g. relapse and often rehospitalisation. There is no published head-to-head comparison of outcomes among first-episode patients receiving LAI drugs and those receiving oral medication. However, non-adherence is a considerable problem in first-episode patients. Many such individuals have not fully accepted the reality of their illness, and since remission of symptoms is common after treatment of a first episode, there is often a false sense of not needing continued medication. In addition, many clinicians assume that patients at this phase of illness would be unlikely to accept LAI medication. There have been two recent studies, however, that challenge this assumption. Emsley et al reported on 60 first-episode patients who were eligible for a study of risperidone LAI. ${ }^{26}$ Only 9 (15\%) refused. Patients were followed for up to 2 years; $72 \%$ completed the 2-year trial. Weiden et al reported on a two-stage model of engagement and then randomisation to treatment with either LAI medication or oral drugs. ${ }^{27}$ Seventy-four patients with a first episode of psychosis consented to an assessment protocol; 46 patients who met diagnostic criteria for a schizophrenia, schizoaffective or schizophreniform disorder and had had less than 16 weeks of antipsychotic treatment were asked to participate in a randomised controlled trial. Eighty-three per cent of eligible patients consented to participate, and $73 \%$ of those who were randomised to LAIs accepted them. Only 12-week follow-up data have been reported, and attitudes towards medication, assessed by masked raters, revealed no significant difference between treatment groups. Medication adherence, on the other hand, was significantly better in the group receiving injections. These studies suggest that the use of LAI medication is feasible in first-episode disorder and may have distinct advantages. Clearly, further research is warranted. A critical question that needs to be addressed is whether or not LAIs can be effective in reducing the risk of nonadherence in people with first-episode illness who, in general, have a high likelihood of becoming nonadherent but have yet to manifest such behaviour.

\section{Treatment-resistant schizophrenia}

There has been remarkably little research addressing the role of LAI drugs in patients with treatment-resistant disorder. It is not really known to what extent non-adherence contributes to the evolution or current manifestation of treatment resistance. For example, few clinicians obtain a drug blood level before considering a patient to be treatment-resistant. It is also possible that repeated exacerbations and relapses due to poor adherence contribute to the evolution of treatment resistance, but this too has not been well studied. Some individuals might experience low bioavailability or rapid metabolism and this could contribute 
to apparent treatment resistance. These potential factors suggest that a trial of LAI medication would be justified, but this not a well-established practice. Ideally, true treatment resistance should be differentiated from the 'pseudo' treatment resistance associated with non-adherence or inadequate blood levels. Certainly research in this area is sorely needed.

\section{Key questions and considerations}

\section{How far have we come in the 10 years since we published guidelines on the use of LAIs?}

It appears that in some countries utilisation of LAIs has increased, but in most there has not been a major change despite the introduction of the first long-acting atypical antipsychotics. Statements have been provided on the indications for LAIs from widely disseminated guidelines on the pharmacologic treatment of schizophrenia, and although we believe that these guidelines are generally too conservative in their recommendations, even these guidelines are infrequently followed.

\section{Who should be considered for depot drugs?}

Any patient for whom long-term treatment is indicated should be considered a candidate for LAI. Patients who are irregular in taking medications are particularly appropriate candidates given the well-established relationship between non-adherence and risk of relapse. Even if patients initially refuse this option, clinicians should work with them (through the therapeutic alliance) to help them understand the potential advantages.

\section{When should the treatment start?}

Treatment should start as soon as possible after the improvement of acute symptoms (oral, or short- or intermediate-acting intramuscular medication is preferable for acute treatment as long as flexibility of dosage is desirable).

\section{Which drugs?}

In choosing a drug the clinician should consider previous experience, personal patient preference, patient's history of response (both therapeutic and adverse effects) and pharmacokinetic properties. There is no definite evidence that any one LAI is superior to another in terms of efficacy, although they may differ in side-effect profile. With the development of additional LAIs more data are available on the effectiveness of these drugs, but unfortunately there are still relatively few welldesigned, head-to-head, long-term comparisons of LAIs and oral medications in the prevention of relapse and rehospitalisation.

\section{Need for additional research}

There are a number of areas where additional research is necessary. There are still too few large-scale, long-term trials assessing the impact of LAIs on outcome. Care needs to be taken to understand the trade-off between naturalistic and controlled trials, as well as between efficacy and effectiveness trials. More research is needed on the potential role of LAIs in patients with a first episode of psychosis, treatment-refractory schizophrenia or comorbid substance misuse.

\section{Conclusion}

The overall recommendations from the 1998 guidelines remain as appropriate today as they were 10 years ago. ${ }^{1}$ Long-acting injections can be a valuable tool in managing schizophrenia and facilitating optimum outcome. Perhaps more data are necessary to develop a broader consensus; however, physician and patient biases and reluctance remain important targets for guidance, psychoeducation and shared decision-making. Given the personal suffering, family burden and societal costs associated with nonadherence and consequent relapse, in our opinion the potential value of LAI medication continues to be inadequately appreciated.

John M. Kane, MD, Department of Psychiatry, Zucker Hillside Hospital, Glen Oaks, New York, USA; Carlos Garcia-Ribera, MD, Hospital del Mar, Institute for Psychiatric Assistance, Mental Health and Drug Addiction (IAPS-IMAS), Barcelona, Spain

Correspondence: Dr John M. Kane, Department of Psychiatry, Zucker Hillside Hospital, 75-59 263 Street, Glen Oaks, NY 11004, USA. Email: psychiatry@lij.edu

\section{Appendix 1}

\section{Case vignette 1}

R.K. was a 20-year-old college student when he experienced his first episode of schizophrenia. He left school and was admitted to hospital near his home. He was treated in the hospital for 4 weeks and then in an outpatient clinic for 6 months. He found a job as an office assistant in an advertising agency through a friend of his father. Eight months following his discharge from the hospital he returned to school to restart his sophomore year in college. At that point he was convinced that he had fully recovered and no longer needed medication. Seven months later he was again admitted to hospital. He never returned to college on a full-time basis, but did try subsequently to take night courses at a community college near his home.

Although we cannot be certain as to the outcome if R.K. had continued with his medication, it certainly would have significantly reduced the risk of a second episode. At this stage of illness one or two relapses can have a major impact in diminishing one's academic, vocational and social opportunities.

\section{Case vignette 2}

K.L. experienced the onset of schizophrenia at the age of 23 years. He was initially hospitalised for 2 months and responded well to antipsychotic medication. Within 4 months of discharge he withdrew from out-patient treatment and discontinued medication. He was readmitted to hospital 5 months later. After 3 weeks in the hospital he was again referred for out-patient treatment. His attendance was sporadic and again he discontinued medication within a few months. After this pattern repeated itself yet again the in-patient staff suggested the possibility of long-acting injection medication.

This case illustrates an all-too-common pattern of hospitalisation, nonadherence and rehospitalisation which often occurs several times before the use of LAl is considered. In some such cases it is never considered.

\section{Appendix 2}

\section{Excerpts from guidelines}

'Depot preparations should be offered as a treatment option where a service user expresses a preference for such treatment because of its convenience or as part of a treatment plan in which avoidance of covert nonadherence to the antipsychotic regimen is a clinical priority.' (NICE Guidelines, 2002) $^{11}$

'Consider long-acting injection antipsychotic medication for patients with recurrent relapses related to partial or full nonadherence. The oral form of the same medication (e.g. fluphenazine, haloperidol and risperidone) is the logical choice for initial treatment.' (American Psychiatric Association Guidelines, 2004) ${ }^{12}$

'Long-acting injection antipsychotic medication maintenance treatment should be available and considered for persons who have a history of 
frequent relapse on oral medication, or a history of problems with adherence on oral medication, or who prefer the long-acting injection depot regimen.' (PORT Recommendations, 2003) ${ }^{10}$

'The Texas Medication Algorithm recommends considering the use of LAls when schizophrenic patients are inadequately adherent at any Stage. ${ }^{15,16}$

'The use of long-acting injection formulations is an evidence-based pharmacologic recommendation for reducing non-adherence in multiple episode patients or persistent positive symptomatic patients. (Canadian Clinical Practice Guidelines, 2005) ${ }^{13}$

\section{References}

1 Kane JM, Aguglia E, Altamura AC, Ayuso-Gutierrez JL, Brunello N, Fleischhacker WW, et al. Guidelines for depot antipsychotic treatment in schizophrenia. Eur Neuropsychopharmacol 1998; 8: 55-66.

2 Kane JM, Quitkin F, Rifkin A, Ramos-Lorenzi JR, Nayak DV. Fluphenazine versus placebo in patients with remitted acute first episode schizophrenia. Arch Gen Psychiatry 1982; 39: 70-3.

3 Crow TJ, MacMillan JF, Johnson AL, Johnstone EC. A randomised controlled trial of prophylactic neuroleptic treatment. Br J Psychiatry 1986; 148: 120-7.

4 Robinson DG, Woerner MG, Delman HM, Kane JM. Pharmacological treatments for first-episode schizophrenia. Schizophr Bull 2005; 31: 705-22.

5 Robinson DG, Woerner MG, Alvir JMJ, Geisler S, Koreen A, Sheitman B, et al Predictors of treatment response from a first episode of schizophrenia or schizoaffective disorder. Am J Psychiatry 1999; 156: 544-9.

6 Harding CM, Zubin J, Strauss JS. Chronicity in schizophrenia: revisited. Br J Psychiatry 1992; 161 (suppl 18): 27-37.

7 Harrow M, Jobe TH. Factors involved in outcome and recovery in schizophrenia patients not on antipsychotic medications: a 15 year multifollow-up study. J Nerv Ment Dis 2007; 195: 406-14.

8 Kane JM, Woerner $\mathrm{M}$, Weinhold $\mathrm{P}$, Wegner J, Kinon B. A prospective study of tardive dyskinesia development: preliminary results. J Clin Psychopharmacol 1982; 2: 345-9.

9 American Diabetes Association, American Psychiatric Association, American Association of Clinical Endocrinologists, North American Association for the Study of Obesity. Consensus Development Conference on Antipsychotic Drugs and Obesity and Diabetes. J Clin Psychiatry 2004; 65: 267-73.

10 Lehman AF, Steinwachs DM, Survey Co-Investigators of the PORT Project. Patterns of usual care for schizophrenia. Initial results from the Schizophrenia Patient Outcomes Research Team (PORT) Client Survey. Schizophr Bull 1998; 24: 11-20.

11 National Institute for Health and Clinical Excellence. Schizophrenia: Full National Clinical Guideline on Core Interventions in Primary and Secondary Care. Gaskell/British Psychological Society, 2003.
12 American Psychiatric Association Work Group on Schizophrenia. Practice guideline for the treatment of patients with schizophrenia, second edition Am J Psychiatry 2004; 161 (2 suppl): 1-56.

13 Canadian Psychiatric Association. Clinical practice guidelines: treatment of schizophrenia. Can J Psychiatry 2005; 50 (suppl 1): 7S-56S.

14 Moore TA, Buchanan RW, Buckley PF, Chiles JA, Conley RR, Crismon ML, et al. The Texas Medication Algorithm Project antipsychotic algorithm for schizophrenia: 2006 update. J Clin Psychiatry 2007; 68: 1751-62.

15 Miller AL, Hall CS, Buchanan RW, Buckley PF, Chiles JA, Conley RR, et al. The Texas Medication Algorithm Project antipsychotic algorithm for schizophrenia: 2003 update. J Clin Psychiatry 2004; 65: 500-8.

16 Argo TR, Crismon ML, Miller AL, Moore TA, Bendele SD, Suehs B. Texas Medication Algorithm Project Procedural Manual. Schizophrenia Treatment Algorithm. Texas Department of State Health Services, 2008.

17 Fenton WS, Blyler CR, Heinssen RK. Determinants of medication compliance in schizophrenia: empirical and clinical findings. Schizophr Bull 1997; 23 . 637-51.

18 Lacro JP, Dunn LB, Dolder CR, Leckband SG, Jeste DV. Prevalence of and risk factors for medication nonadherence in patients with schizophrenia: a comprehensive review of recent literature. J Clin Psychiatry 2002; 63: 892-907.

19 Velligan DI, Lam F, Ereshefsky L, Miller AL. Psychopharmacology: perspectives on medication adherence and atypical antipsychotic medications. Psychiatr Serv 2003; 54: 665-7.

20 Velligan DI, Wang M, Diamond P, Glahn DC, Castillo D, Bendle S, et al. Relationships among subjective and objective measures of adherence to oral antipsychotic medications. Psychiatr Serv 2007; 58: 1187-92.

21 Kane JM, Rifkin A, Quitkin F, Nayak D, Ramos-Lorenzi J, Klein DF, et al. Low dose fluphenazine decanoate in maintenance treatment of schizophrenia. Psychiatry Res 1979; 1: 341-8.

22 Kane JM, Rifkin A, Woerner M, Reardon G, Sarantakos S, Schiebel D, et al. Low-dose neuroleptic treatment of outpatient schizophrenics: I. Preliminary results for relapse rates. Arch Gen Psychiatry 1983; 40: 893-6.

23 Schooler NR, Keith SJ, Severe JB, Matthews SM, Bellack AS, Glick ID, et al. Relapse and rehospitalization during maintenance treatment of schizophrenia. Arch Gen Psychiatry 1997; 54: 453-63.

24 Waddell $\mathrm{L}$, Taylor M. Attitudes of patients and mental health staff to antipsychotic long-acting injections: systematic review. Br J Psychiatry 2009; 195 (suppl 52): s43-50.

25 Gray R, Spilling R, Burgess D, Newey T. Long-acting injections in clinical practice: medication management and patient choice. Br J Psychiatry 2009; 195 (suppl 52): s51-6.

26 Emsley R, Medori R, Koen L, Oosthuizen PP, Niehaus D, Rabinowitz J. Longacting injectable risperidone in the treatment of subjects with recent-onset psychosis. J Clin Psychopharm 2008; 28: 210-3.

27 Weiden PJ, Schooler NR, Weedon JC, Elmouchtari A, Sunakawa A, Goldfinger SM. Long-acting injectable risperidone vs. continuing on oral atypical antipsychotic for first-episode schizophrenia patients: initial adherence outcomes. J Clin Psychiatry in press. 